\title{
INTERVIEWING THE TRANSLATOR
}

\section{"I am not trying to move into an ivory tower of pure art..." \\ An interview with Prof. Sukanta Chaudhuri}

Sukanta Chaudhuri (born 1950) is an internationally

renowned scholar of English literature of
the Renaissance period. He
works in the fields of European
Renaissance studies,
Translation, and Textual
Studies. He has authored
severalbooks like Infirm Glory:
Shakespeare and the
Renaissance Image of
Man(Oxford: Clarendon

Press, 1981), Renaissance Pastoral and Its English Developments (Oxford: Clarendon Press, 1989), Select Nonsense of Sukumar Ray (New Delhi: OUP, 1998), Translation and Understanding (New Delhi: OUP, 1999), Shakespeare without English (New Delhi: Pearson Education, 2006), edited select Elizabethan poetry and essays by Francis Bacon for Oxford University Press.

He has edited and co-edited several collections of essays on the Renaissance period. He had also remained General Editor of the Oxford Tagore Translations (five volumes published between 2000 and 2006). He has translated extensively from Bengali writers and Bengali poets like Rabindranath Tagore, Bankim Chandra Chattopadhyay, Sarat Chandra Chattopadhyay, Sukumar Ray, Rajshekhar Bose and others. 
Sukanta Chaudhuri is currently teaching at Jadavpur University, Kolkata, West Bengal.

He talks about the various issues of translation ranging from his experience as a translator to the translation of knowledge texts in the country. Here is an excerpt from the interview* with Prof. Sukanta Chaudhuri.

\section{Q: How do the models or theoretical intricacies of the text impact the translator while translating, does it do so at all?}

SC: I would say it does not or at least it should not. I can say this certainly happens when I do translation myself. I find myself focusing entirely on the text, the nature of the text, and the challenges of the text. I try to see the intricacies of the source language and how I can render it into the target language. The challenges that concern me are the actual verbal problems, the problems of language, etc. I do not, at all, think of any kind of theoretical model, any agenda or any purpose for which I am undertaking the translation. Frankly, I would go so far as to say that if a translator starts translating with some kind of exterior purpose in mind then that is bad for a translation.

One may say that any author, when he writes, should think only about what he is writing. He should not, at that point, think of the target reader. And even for translation, it is true. It is perhaps especially true because, after all any exercise in translation is an exercise in cultural politics. Two languages, two cultures conveyed by those languages have a kind of encounter when they meet. Afterwards either you can theorize about it, or other people can theorize about it. But if at the moment of translation, you are taken up with those matters of broader cultural encounter or cultural politics, then that will certainly affect the actual nature of your translation. It will be fatal, I think. Not only I think along these lines, but if anybody tries to suggest it to me, I think I would also deliberately reject that suggestion and try to keep all these considerations out of my mind.

\footnotetext{
* Interviewed by Abhishek Sarkar, Sanhita Dasgupta and Chandan Biswas of National Translation Mission, an initiative by the Ministry of Human Resource Development, Government of India with Central Institute of Indian Languages as its nodal agency.
} 


\section{Q: How does the political underpinning of the text influence the process of translation?}

SC: There can be a political and theoretical underpinning to a text. Not only there can be, but there should be and there must be such an underpinning both when writing the original text and necessarily while translating the text. Since translation is an exercise in cultural politics, obviously I am not denying that role. I am not trying to move into an ivory tower of pure art; far from it. The factor of social engagement or even political engagement - by political, of course, I don't mean particular political party or electoral politics, but in the broader sense those are the forces which shape and guide our society-must be there in any writing, even if that is a love poem or a novel. But while engaged with the act of translation rendering the language should be the uppermost consideration not the ultimate purpose. The original writer might certainly had had the purpose in mind, but even he, I should say, was also paying attention to language in which he was expressing his views and shaping his agenda. Concentrating on the ultimate purpose at the moment of writing definitely affects the quality of writing, and therefore the purposes are also likely to suffer. Your writing will not be convincing to the target readership. Same is the case with translation. If I am translating political texts or even a propaganda, it is very likely that my purpose would also be propagandist. I share the ideology of the original writer; therefore I want to reach it to the target reader who may not be able to access the original texts. So my ultimate purpose may certainly be political; but during the execution, I would definitely think of considering the means rather than the end.

\section{Q: The current translation scenario in India-your observations...}

SC: I am not fully aware or well informed about the total scenario. One thing has certainly struck all of us who do any translation at all that, there seems to be a much greater demand for translation now. Over the last few years, every now and then, major, important publishers have approached us not only with proposals for us to translate but also 
wanted our suggestions about other people whom they can contact for the same. So, it certainly seems that there is a much bigger demand and market for translation than there was in the past. I try to think about the possible reasons for this. One reason, I think, has to do with the great international rise of Indian writing in English. This has created the very unfortunate impression that all significant Indian literature is written in English language. But at the same time, there are people who are trying to correct this impression. Many major publishers in India and abroad would be actually interested in undertaking major translation programs to create a list of important translations from Indian languages into English. So that way, the outlook is certainly promising. If anybody wants to publish good English translation of any major Indian literature, they would readily find publishers.

Another issue to ponder about is that though there is a demand for translation, on the whole, the reward of translation, both financial and by way of fame and recognition, is less than original writing. That is why in our country we practically do not have professional translators. In the West, there are many people who earn excellent living by doing translations. But there are few such people in our country. Therefore, the demand is hardly met and this continues to foster that unfortunate impression that not enough good literature is being written in the Indian languages. I, sitting in Bengal, may not know what good literature is coming out in Marathi or Tamil or in Hindi. So there are problems with meeting this demand and in such a situation, some translations are published to fulfill the demand which may not be very good and lead to damage either the reputation of original writers or put people off reading translations.

\section{Q: How would you define a good translator?}

SC: The problem is that there are relatively few good translators available. Somebody who may know both languages very well may still not make a good translator. There is a remark by Rabindranath that if two able bodied men lean on each other's shoulders they don't walk faster-they hold up each other's progress. In the same way, I 
think the person might know very good Bengali, he may know very good English and is able to write very good English himself. But that does not necessarily make him a good translator. His translation will be too independent to follow its own course and he will not pay enough attention to the original; or else he may feel that he needs to follow the original so closely that the translations will not be very attractive and readable. In fact, if somebody knows good English, this latter danger might increase. That is why finding a good translator is really a very difficult task. It's a very rare discovery.

\section{Q: Translators are licensed to transcreate-your comments...}

SC: On the whole NO. I think the translator should not go very much for original creation. Let us think of two different types of translators. One is an original writer in her own right or at least, she has the creative power. She may not have actually published much but she has a creative power. Such creative writers might actually use another person's writing for translation as a kind of launching pad for their own creative process. So works produced under such circumstances are technically translations; but their actual purpose is not simply to make a work available to read in another language. Their actual purpose is to relieve creative energy in the translation where the translator is actually setting about the task as a creator. Let that be one model. The other model might be a person who has less talent, less capacity, does not have any truly creative spark. Her purpose in translating is chiefly to act as a mediator - to take a work from one language and make it accessible to readers in other languages. You will never find a translator who is $100 \%$ conforming to one model or the other. These are the two extremes and there is a whole range in between. It's a matter of the degree to which they are balanced or combined.

To this day, one of the least successful functions of the computer has been machine translation. Two languages obviously can't ever completely overlap. Even within the same language, no two words have the same semiotic range and obviously between two different languages you will never find two words with the same semiotic range. The translator essentially has to use her judgment. There has to be a 
constant exercise of judgment, a constant response to the implications of both Source and Target Languages. So in that sense you may say any translator has to be not less creative but more creative than an original writer. If the translator therefore says, "I want to produce a work which has become an independent interest, I will translate author $\mathrm{X}$. But I want my reader to read that work in order to read me, rather than the author X"- that is something dangerous. It argues for a degree of self-assertion in a translator where she wants to prove herself more important than the original writer. Otherwise the basic virtue of a translator has to be humility. The translator always has to hasten to keep herself a little humble. She is ultimately aiming to project the original writer not herself.

\section{Q: Your experience as a translator...}

SC: I have mostly translated poems. I translated a good deal of Rabindranath's poetry for the Oxford Tagore Translation. I'm the General Editor of the Oxford Tagore Translation. I have also translated a lot from Sukumar Ray and Jibanananda Das. I have translated Nirendranath Chakrabartee's Ulanga Raja (The Naked King) and I have done some stray translations of many other Bengali poets and edited volumes of such translations. I have also translated a lot of nonfictional prose.

Let me share a very interesting experiment in translation in which I took part. This was carried out in the English Department, Jadavpur University. The person who really inspired this whole exercise and was in charge of the project was my late colleague Prof. Arup Rudra. It was his idea that we might try to translate Sharathchandra's novel Shesh Prasna (Final Question) which had never been translated before. The actual translation was done under Arup Babu's supervision by a number of our research students; not as a formal research project but just as an exercise, for pleasure. Each of them translated a part of that book according to some of the initial instructions that Arup Babu had given. Arup Babu monitored the whole translation to make sure that there is parity of treatment. After the whole book 
was complete, I went over the entire translation because Arup Babu said he was too involved with the text to make any impartial judgment. So I took a look at that whole translation and tried to induce a basic note, a basic register at the level of the translation. This translation was published by Ravi Dayal Publishers with the title Final Question. It is now reprinted by Penguin Translations. It has proved quite successful.

\section{Q: Your experience of translating Abol-Tabol ...}

SC: I did it chiefly for my own amusement. Apart from a few stray poems, Abol-Tabol and Ha-ia-ba-ra-la were the first major translations I ever undertook. That time my son was very small. I used to read it to him in Bengali and one day I just felt that I could try and see how it works in English. It was just for my own satisfaction. At that time I had no idea that I would ever complete the whole book or publish it. My chief purpose was to see how far I could bring out these effects of the Bengali in English. Now, in one way it was relatively easy because they were nonsense verses. One could take liberty which one can't take with serious verses. While translating Rabindranath or Jibanananda, my policy at least would be to try to stick as closely as possible to the original. I cannot depart very far from Rabindranath, because I would be falsifying a text, which many people read seriously, sometimes almost with the worshipful sprit. Since nonsense literature is written for fun, one can take liberty. So in some cases, I have had more freedom while translating nonsense verses of Sukumar Ray than I would have dared to take while translating other poets. To give one example, sometimes I've even introduced a couple of things which was not there in the original. For instance, in the poem "chayabaji", there is the bang who makes a living by capturing shadows of trees. There is one point where in my translation the man says that the juice or sap of a particular tree induces sound sleep and a musical snore. Now the idea of musical snore is not there in Sukumar Ray actually; but I thought it was a nice and interesting idea. Though, at some points I could not even employ this method. I think, in fact, there are some half-a-dozen poems which I could not translate. I tried but I failed. So 
I left those out. Rather than produce a translation that clearly did not work, I thought it would be best to omit them all together. Since I could take more liberty in translating some of the poems, there was a kind of exhilaration.

According to my experience, the real challenge was not finding the equivalence of particular words. The biggest challenge is finding equivalence for the tone, the movement, the spirit of the whole piece. If once you capture that, the words will come or even if the words don't come, the total effect will come. Then if a particular rendering is not exactly accurate, it does not matter much. Especially with nonsense, comic poetry the movement of the verse is very important. There must be no faltering, no vagueness, no hesitation. It must be very smooth, very brisk and my greatest challenge really was to try to preserve that in the translations as much as I could. Well, I've done the best I could.

\section{Q: It is commonly believed that prose is easier to translate than poetry-your comments...}

SC: Well YES and NO. I mean there is one huge challenge in translating poetry, which is not there in prose obviously. In poetry there is the matter of rhymes, stanza form, prosody, metrics etc. But apart from that, I would really say that the challenges of prose translation are not few or less. They are simply subtle; especially in fiction involving dialogues. If there are dialogues, there would be characters. If the original is written by a good author, then the dialogue of each character would have particular flavor, register or angle. No two characters speak alike. So the translation should also bring out the differences. This can be extremely difficult because if there are some slight differences in idiom, choice of words, increase in sentence structure between the various speakers of the original, then you have to find the equivalent in translation. The same problem arises in drama also. If there is a character in drama who speaks in dialect or who speaks some kind of broken Bengali-who is not a Bengali but speaks the language, or speaks Bengali with particular accents, then it would be a challenge to translate that dialogue. Dialogues can be extremely tricky. Even nonfictional prose produces challenges. 
The sentence structures of each language are different. So if you have some intricate thoughts, which in one language might be expressible in a single long sentence since the grammatical rules of that languages allow long sentence structure to carry complex thought, the reader can follow it. But if translated into other languages using the same sentence structure, then that may not work. I translated some of Rabindranath's critical writings of literature into English. I had found what in Rabindranath was a single long sentence had to be broken up in English into maybe two shorter sentences, because if I wanted to keep the sentence structure intact then it would become very cumbersome in English and difficult to follow.

There is another related problem which in fact relates both to prose and poetry, but may be more important in case of prose where the idea communicated is more important. There is a kind of translators' fetish that one word in the original must always be translated by the same word in the translation. I myself don't agree and I found it is not possible. No two words have same semantic range; especially between two languages. So the same word in original language might have five different implications which in the target language are better represented by five different words. If I use the same word in all five cases, then maybe only in one case I might get the correct nuance whereas there might be some better word/s in the target language which will allow me to express the nuance properly. So at least I would not hesitate to change the rendering if I knew some better word, if the context demanded it. Prose translation especially has to be contextual. There are two contexts: one meaning and other grammatical. Every word in a sentence takes its place in a total grammatical structure with other words. Depending on the other words of the sentence, the relationship which it is in with those words, the function, the meaning of this word would change. That is to be reflected in different sentence structure or may be in choice of different words.

\section{Q: Do you think a translator should be culturally more equipped than linguistically?}

SC: I don't think you can prioritize. Both are equally important. I don't seek to separate them. I simply say that these are aspects of one 
single quality. Language is a social phenomenon. To understand the way language works is to understand the way society works; the way people use and understand it. Especially in case of translation, this is important because you are not simply rendering one language to the speakers/readers of another language; you are also rendering one culture and society to the members of another culture and society. So, social awareness should get communicated through languages.

\section{Q: Knowledge text translation* — your comments...}

SC: Let me make two or three points. If we talk about text books, then there is a huge need. First of all, a text book should be translated by somebody who has specialized domain knowledge. For example, if it is a Physics text book, then the translator should know about Physics. It's not enough if she knows English and Bengali well. Very sadly in our society, we have not yet developed the need for a specialized translator. Given the vast market for text books at all levels, one would imagine that a person would make a very good living by translating text books or other books in a particular subject. But this also has something to do with the way our society and our educational system is compartmentalized. Somebody who studies Physics is cut off from Linguistics. Somebody who knows the particular subject does not have commensurate command over a language. So they cannot balance these two skills. Of course there are exceptions, but they are few. I think this is a moment of maturity requiring grand development of human resources. Firstly, courses need to be set up which would train people. But of course if people are trained, then the implication is that they must have something to do. So that demand for work needs to be created. There is however another point to be made. Some attempts have been made in our country, at least at the college level, to translate

* Translating the knowledge texts used at the undergraduate and postgraduate levels in the education system of India has been one of the chief objectives of National Translation Mission. 
text books from English into Bengali or some other Indian languages. Later, the publishers were disappointed because their books had not been popular.

\section{Q: Your suggestions for translating a knowledge text...}

SC: I don't think you can just translate a text book, word for word, from of one language and society into another. A text book written in English for students in England or America will not do even for English medium school students in India. Even if you leave the language issue, you need to adapt the material for the students in India. Even in a text book in a supposedly neutral subject like Mathematics, Physics you imagine that sociological or geographical differences do not matter; but they do. Partly they do in the matter of examples. Say the problems in a Mathematical text book involve names such as John has 25 cattle and Tom has 40 cattle, so on and so forth. In this case, you use Indian names. That is easily done, but it is not as simple as that. It is difficult to pin point these with examples, but there is a kind of deeper social adaptation which is also necessary. And with textbooks, which concerns ideas, this is even more necessary. So in fact what is required is the production of what would be original text books. But again paradoxically, one might almost say that the translator of such text books needs more creative input than the translator of a poetry. 